\title{
IMAGENS, ESCRITAS E TEXTOS PARA A FORMAÇÃO PARTICIPATIVA EM CONTEXTOS EDUCATIVOS
}

\author{
Lincoln Tavares Silva ${ }^{1}$
}

CAP-UERJ

\section{RESUMO:}

Neste texto reflito sobre vivências de/em formação de professores numa trajetória que triIhei ao longo dos últimos anos, incorporando, de forma efetiva, a linguagem visual às minhas práticas docentes cotidianas. Neste trabalho, destaco duas experiências de minha carreira como professor. Elas se deram em espaçostempos (conforme nos realçam os pesquisadores do cotidiano escolar) diferenciados e complementares. No primeiro, estava eu como docente e pesquisador interessado em articular o uso das imagens às minhas práticas e a pesquisas, vivendo predominantemente processos de aprendizagem e formação. Além de mim, outros sujeitos, de formações variadas e também em formação, participaram ativamente de atividades propostas, conjugando processos de produção de conhecimentos por meio das imagens. Na outra experiência, um ano depois, era eu sujeito deste processo, a colaborar com outros docentes, ministrando curso de formação continuada para professores da rede municipal do Rio de Janeiro. Ambas foram experiências de trocas profundas, marcadas por momentos múltiplos de ensinaraprender, vividos indistintamente por mim, por outros sujeitos e pelos docentes envolvidos. Tomo como fundamentos os constructos teóricos a respeito da linguagem e cultura visual, considerendo a análise da representação imagética e da pesquisa sobre a imagem como fonte de conhecimento. Associo outro constructo referente à Teoria das Representações Sociais, conforme sua configuração nos estudos de Serge Moscovici e Denise Jodelet. A partir de um conjunto de imagens e representações extraídas em diferentes situações cotidianas, proponho reflexões, cujas temáticas voltam-se para a possibilidade de construção de um novo pensamento no que se refere ao papel dos grupos, nos seus contextos socioambientais e sócio-educativos, ambos inseridos na sociedade contemporânea.

PalaVRas-CHAVe: formação de professores - imagens e educação ambiental - representações Sociais.

\section{ABSTRACT:}

In this text, I reflect about experiences on teacher education that we live over the last few years to incorporate, effectively, the visual language to our everyday teaching practices. In this paper, I highlight two experiences of my teaching career which happened in different and complementary "spacetimes". At first, I was as a teacher and researcher interested in articulating the use of images to my practice and research, living predominantly learning processes and training. Besides me, other subjects of varied backgrounds and also in training, 
e-Mosaicos - Revista Multidisciplinar de Ensino, Pesquisa, Extensão e Cultura do Instituto de Aplicação Fernando Rodrigues da Silveira (CAp-UERJ) ANO 1 - V. 1 - N. 1 - JUNHO 2012 - ISSN: 2316-9303

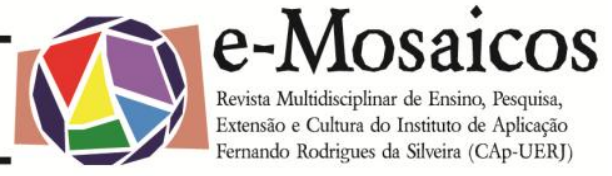

actively participated in the activities proposed, combining processes of knowledge production through the images. In another experiment, a year later, I was the subject of this process, collaborating with other teachers, teaching continuing education course for teachers from the city of Rio de Janeiro. Both, in fact, were experiences of profound changes, marked by multiple moments of lived "teachingandlearning" indistinctly for me, for other subjects and the teachers involved. I take as basis the theoretical constructs obtained by reflections about language and visual culture, contemplating the analysis of imagery and representation of research on the image as a source of knowledge. I recommended to associate this construction with another construct referring to Social Representation Theory, based on configuration from studies of Serge Moscovici and Denise Jodelet. From a set of images and representations extracted in different everyday situations, reflections were proposed, whose thematic pointed to the possibility of building a new thinking regarding the role of groups in their environmental and socio-educational contexts, both inserted in contemporary society.

KEY WORDS: teacher education - images and environmental education - social representations.

\section{INTRODUÇÃO}

0 texto ora apresentado reflete vivências de/em formação de professores numa trajetória que vimos trilhando ao longo dos últimos anos, ao incorporamos, de forma efetiva, a linguagem visual às nossas práticas docentes cotidianas.

É quase consensual que vivemos num "mundo de imagens", onde há um predomínio do que alguns autores chamam de "cultura visual", que tem despertado o interesse de várias áreas ou campos do conhecimento. Todavia, nem sempre foi assim e as representações visuais durante longo tempo foram tomadas de forma discriminada e apartadas nas análises sobre a importância de seu papel na configuração do conhecimento produzido.

Ueócka (2002) já sinalizara que a fonte escrita tem sido o alicerce da pesquisa acadêmica, consistindo no material sobre o qual se debruçam os estudiosos para desvendar, entender, interpretar, analisar e reconstituir enredos e contexto sociais. Para além desta constatação, acreditamos que o papel da associação entre as imagens e os textos relacionados ao entendimento e à constituição de ações e saberes, em espaços formais e não-formais de aprendizagem e convívio, constitui-se numa poderosa ferramenta de compreensão do real e das ações que a sociedade produz sobre o mesmo.

Neste trabalho, destaco duas experiências de minha carreira como professor. Elas se deram em espaçostempos diferenciados e complementares. No primeiro, estava eu como docente e pesquisador interessado em articular o uso das imagens às minhas práticas e a pesquisas, vivendo predominantemente processos de aprendizagem e formação. Além de mim, outros sujeitos, de formações variadas e também em formação, participaram ativamente de atividades propostas, conjugando processos de produção de conhecimentos por meio das imagens. Tal vivência ocorreu em Joinvile, no V Congresso Íbero-americano de Educação Ambiental. A atividade de que falo foi ministrada pela professora Claudia Mariza Mattos Brandão (FURG).

Na outra experiência, um ano depois, era eu sujeito deste processo, a colaborar 
e-Mosaicos - Revista Multidisciplinar de Ensino, Pesquisa, Extensão e Cultura do Instituto de Aplicação Fernando Rodrigues da Silveira (CAp-UERJ) ANO 1 - V. 1 - N. 1 - JUNHO 2012 - ISSN: 2316-9303

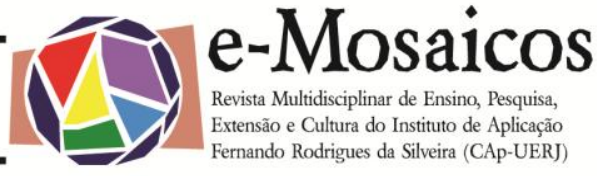

com outros docentes, ministrando curso de formação continuada para professores da rede municipal do Rio de Janeiro. Ambas, em verdade, foram experiências de trocas profundas, marcadas por momentos múltiplos de ensinaraprender vividos indistintamente por mim, por outros sujeitos e pelos docentes envolvidos.

Mais que um relato, pretendo deixar marcas de um caminho que entendi ser bastante prazeroso para a formação docente $\mathrm{e}$ para a aplicabilidade de práticas educacionais múltiplas, leves e exatas conforme nos apontara Calvino (1990).

Antes, porém, cabe trazer a tona algumas considerações sobre o papel das imagens em associação às escritas e às leituras para o trabalho no cotidiano escolar. Muitos já vêm "escrevendo" sobre isso, mas entendemos que muitos ainda não "escutaram falar" sobre isso.

\section{SEM ENQUADRAR: 0 USO DAS IMAGENS E REPRESENTAÇÕES NA SIGNIFICAÇÃO DE CONHECIMENTOS}

O desenvolvimento das novas tecnologias da comunicação, o poder dos fluxos de informação, das finanças e das mercadorias vem sendo acelerado por um processo universalizante de diminuição das distâncias, tanto têmporo-espaciais, quanto intersocietárias (HARVEY, 2000).

De acordo com Lima e Silva (2002), as novas tecnologias de comunicação, principalmente as que geram imagens visuais, são apresentadas, frequentemente, como algo que produz a manipulação e a resistência, bem como a homogeneização e a fragmentação da cultura contemporânea e uma maior densidade de intercâmbios. Esta característica de universalidade da imagem facilita o processo de globalização, que bus- ca meios acessíveis de penetração internacional e de manipulação (aparências e ilusões). As imagens vêm sendo encaradas como parte necessária ao processo de formação das sociedades, sobretudo em virtude de sua capacidade de alcançar um maior número de pessoas.

Ao participar ativamente desse momento, as imagens se estabelecem como disseminadoras de mensagens que promovem um conhecimento comum e uma maior divulgação dos fatos. Não nos iludimos que entre estes fatos há os que contribuem para o fortalecimento do discurso dos grupos dominantes, permitindo que as culturas locais/regionais sejam influenciadas por outras culturas a partir do estabelecimento de padrões de conduta.

Quando optamos em discorrer neste ensaio sobre o uso de fontes de informação e representação não textuais, temos como objetivo superar o uso de imagens que, em geral, simplesmente emolduram um discurso, dando-lhe legitimidade e credibilidade. Em nosso entendimento, incorporar a cultura visual à pesquisa sócio-educacional vai além disso.

Segundo Fischman (2004), é possível argumentar que a contenda em relação à cultura visual poderá vir a ser um obstáculo importante de se superar, pois, como também mencionara Larrosa (1998, p.213), "é sempre interessante saber por que um campo proíbe ou ignora algo... omissões e proibições são as melhores formas de conhecer a estrutura de uma disciplina, as regras que a estruturam e sua gramática profunda".

As imagens e representações produzidas, por meio de sua força, podem, em várias ocasiões, suplantar o poder das palavras, transformando-se em tática de persuasão criadora de ações inspiradoras e concre- 
e-Mosaicos - Revista Multidisciplinar de Ensino, Pesquisa, Extensão e Cultura do Instituto de Aplicação Fernando Rodrigues da Silveira (CAp-UERJ)

ANO 1 - V. 1 - N. 1 - JUNHO 2012 - ISSN: 2316-9303

tas de transformação social, com sentido e eficácia sociais.

Hoje, falar da ameaça de extermínio da cultura $^{1}$ e da identidade de sociedades é questionar o potencial de transformação e de fusão que acontece na base da existência destas sociedades.

Acreditamos ser improvável produzir meios que permitam às comunidades e aos sujeitos avaliarem o impacto das condições vividas e proporem saídas para superação das dificuldades encontradas, sem algo para informar sobre a origem, a identidade, sobre a prova de sua existência e de sua realidade.

Deste modo, o texto aqui proposto se inspira na interação dialógica dos sujeitos ${ }^{2}$

1 Relembramos Certeau (1995, p.273), para quem "[...] é sempre bom recordar que não se devem tomar os outros por idiotas". Certeau em suas obras, principalmente em $A$ Cultura no Plural, contestou a postura etnocêntrica de Marx em sua referência à situação cultural do embrutecimento do campesinato. Também criticou Adorno e Horkheimer pela interpretação extremada do impacto idiotizante dos meios de comunicação de massa sobre as pessoas e rejeitou concepções de cultura, geralmente compartilhadas pelas elites culturais, segundo as quais os não letrados são naturalmente inferiores e imbecis. Também repudiou a concepção difusionista em antropologia, a qual se sustenta no postulado de que os bens culturais eruditos são difundidos unilateralmente para os círculos populares. Deste modo, Certeau não partilhou da visão simplista de difusão cultural e apontou para a concepção de cultura que se produz numa contínua relação que se dá tanto de "cima" para "baixo" quanto de "baixo" para "cima".

${ }^{2}$ Segundo Bakhtin (1997), as pessoas vão se constituindo como sujeitos nas sucessivas interações, nos diversos espaços discursivos e pode-se presumir que a subjetividade se forma pelos "olhos dos outros". É só ocupando o lugar do outro, o lugar "de fora" que o homem consegue ver a si mesmo e iniciar sua constituição enquanto sujeito. Nesta perspectiva, há sempre um "inacabamento" constituinte, que é dado pelo lugar que o(s) outro(s) ocupa(m) nas sucessivas interações. Esse "inacabamento" do sujeito está diretamente relacionado ao conceito que Bakhtin desenvol- entre si e com a realidade, situados no quadro de representações que os move e orienta suas condutas sócio-educativas nos espaçostempos nos quais convivem cotidianamente.

Para tanto, tomarei como fundamentos os constructos teóricos obtidos pelas reflexões a respeito da linguagem e cultura visual, contemplando a análise da representação imagética e da pesquisa sobre a imagem como fonte de conhecimento. A eles recomendamos associar outro constructo referente à Teoria das Representações Sociais, conforme sua configuração nos estudos de Serge Moscovici e Denise Jodelet.

Cabe salientar que nosso trabalho entende como fundamental a perspectiva da educação pelo olhar, fazendo a interface entre as imagens e suas leituras e as linguagens que representam o mundo de maneira mais codificada. Compreendemos que a Educação ${ }^{3}$ pode tanto reforçar formas habituais e massificadas de entendimento da realidade, quanto encontrar outros jeitos de significá-la, de olhar o mundo, de buscar outros entendimentos e caminhos.

ve a respeito do excedente de visão, que seria o que os outros vêem dele e que ele não vê, como se fosse uma "paisagem de fundo". Assim, o sujeito, incompleto, só existe nas relações com as pessoas, as quais definem os limites. Como as relações são sucessivas e infinitas, não se tem nunca um sujeito absoluto. Ele é sempre resultado de um passado e uma expectativa do que pode vir a ser no futuro.

${ }^{3}$ Com base em Madeira e Alloufa (1995, p.15) entendemos que a "[...] educação é um processo de construção pessoal e social das representações dos indivíduos e grupos. Ela é a relação interpessoal e grupal do ensinar e aprender, na interação de um processo histórico, contextualizado em um espaço e um tempo. Isto abre outra via para a consideração da cultura, em sua relatividade e em sua universalidade [...]". Ainda segundo Madeira (2001, p.125), neste processo "[...] a cultura e o conhecimento são continuamente, transmitidos e (re)construídos, envolvendo a totalidade do sujeito em suas relações com o(s) outro(s)[... $]^{\prime \prime}$. 
e-Mosaicos - Revista Multidisciplinar de Ensino, Pesquisa, Extensão e Cultura do Instituto de Aplicação Fernando Rodrigues da Silveira (CAp-UERJ) ANO 1 - V. 1 - N. 1 - JUNHO 2012 - ISSN: 2316-9303

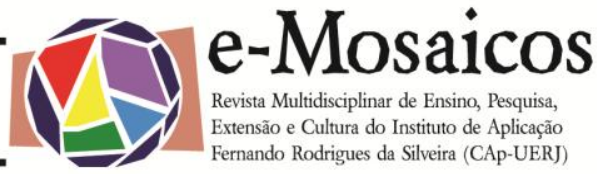

Até o aparecimento recente dos primeiros processos de notação linear dos sons (quatro mil anos), a imagem ocupou o lugar da escrita. Aos poucos a escrita foi ganhando espaço e assumindo uma certa soberania em relação às imagens, até adquirir proporções gigantescas no século XV, com a invenção da imprensa (DEBRAY, 1992).

Para Fischman (2004), o ceticismo sobre a relação entre palavras e imagens é traduzido não apenas no abandono das imagens gráficas, como ferramentas válidas na pesquisa, mas também pelo apartamento da cultura visual em geral. Machado (2001) ponderou que na história da cultura humana brota o retorno, de tempos em tempos, da iconoclasia (do grego eikon, imagem, e klasmos, ação de romper) se manifestando como forma de extrema rejeição às imagens.

A interdição das imagens é um dos dogmas fundamentais da tradição judaicocristã, e se configurou já nos textos bíblicos do Velho Testamento. Esta proibição não se refere somente à imagem divina, mas também a quaisquer tipos de imagens que representem as coisas na terra. $\mathrm{O}$ islamismo também aprofundou o interdito das imagens em quase todos os momentos de sua história. Na Grécia, as imagens não foram proibidas, mas o iconoclasmo tomou corpo no campo intelectual, principalmente na Filosofia. Platão entendia a imagem como simulacro, uma imitação que fascina os tolos e as crianças, ou seja, uma representação falsa do que não existe ou do que não é verdade. Algo que está em lugar de outra coisa, que pode ser fabricado.

Aristóteles entendia as imagens como coisas sensíveis, só que sem matéria, como produto da imaginação, sensação, ou percepção de quem as recebe, ou ainda, como o caráter ou a origem sensível das ideias ou representações de que o homem dispõe. Segundo Abbagnano (1998, p.537) Santo Agostinho dizia que

As imagens são originadas por coisas corpóreas e por meio das sensações: estas, uma vez percebidas, podem ser facilmente lembradas, distinguidas, multiplicadas, reduzidas, ampliadas, organizadas, invertidas, recompostas, de modo que mais agrade ao pensamento.

Também no Império Bizantino, foram proibidas as manifestações com imagens, ao mesmo tempo em que os adeptos da iconofilia e da iconolatria foram duramente perseguidos. Mais tarde, na Idade Moderna, com a Reforma Protestante, novamente a destruição dos ícones se deu, muito em função do corrompido exagero da expansão da idolatria. Este período representou uma cisão no interior do próprio cristianismo.

Segundo Machado (2001), estes diferentes momentos se ancoram numa crença inabalável no poder, na superioridade e na transcendência da palavra, sobretudo da palavra escrita, e para o autor, não é descabido caracterizar o iconoclasmo como uma espécie de "literolatria" - culto do livro e da escrita.

Quando não rejeitada, a tradição imagética era inferiorizada como forma de conhecimento. Este fato se evidencia nas palavras de repreensão do Papa Gregório I ao Arcebispo de Marseille, após o mesmo ter ordenado a destruição de todas as imagens existentes, "...aquilo que a escrita fornece às pessoas que lêem, a pintura fornece aos analfabetos (idiotis) que a contemplam, pois esses ignorantes podem ver aquilo que eles devem imitar". 
e-Mosaicos - Revista Multidisciplinar de Ensino, Pesquisa, Extensão e Cultura do Instituto de Aplicação Fernando Rodrigues da Silveira (CAp-UERJ)

ANO 1 - V. 1 - N. 1 - JUNHO 2012 - ISSN: 2316-9303

Após estes ciclos alternados de iclonoclasia (judaico, bizantino e reformista), atualmente Machado nos chama a atenção para um quarto iconoclasmo ou um neoplatonismo que, para o autor, estaria endemonizando as imagens. Este iconoclasmo estaria sendo empreendido por pensadores contemporâneos importantes como Debord (1967), Fulchignoni (1972), Jameson (1997) e, principalmente, por Baudrillard (1995).

Além do próprio Machado, especialmente no pensamento latino-americano, pensadores como Martin-Barbero (1993), Gómez (1991) e Canclini (1998) levantaram vozes e expressões contrárias a esta demonização das imagens. Tais autores compreendem que o papel efetivo que as mídias desempenham nas sociedades contemporâneas não é algo dado a priori, ou realizado por alguma fatalidade histórica intransponível, sendo, ao contrário, resultado de um intrincado processo de negociação de sentido entre os signos (as imagens culturais produzidas por esses meios), as realidades de que eles tratam ou que criam e os intérpretes que se interpõem entre tais signos e realidades, as instâncias sociais que lhes dão sentido.

Entendemos, em conformidade com o grupo latino-americano, que este embate calca-se em dicotomias falsas, pois, como já afirmara Machado (2001, p. 22), "A escrita não pode se opor às imagens porque nasceu dentro das próprias artes visuais, como desenvolvimento intelectual da iconografia". Se for verdade que a imagem está na origem de toda escritura, e, nesse sentido, a escrita verbal é tão somente uma forma altamente especializada de iconografia, também é verdade que a imagem nunca deixou de ser uma certa modalidade de escritura, isto é, um discurso construído a partir de um processo de codificação de conceitos plásticos ou gráficos. Compreendemos que é nas interfaces das linguagens visuais, orais e escritas que residem a riqueza e a complexidade dos processos comunicativos.

É por meio destas relações dialógicas que nos baseamos para entender a complexidade dos contextos sócio-educativos dos grupos e sujeitos ${ }^{4}$ e tentamos não somente antagonizar, mas principalmente complementar e contextualizar a construção social de temas significativos (política, saúde, meio ambiente, emprego, violência etc.) abordados de forma verdadeiramente pertinente pelos mesmos, para e pela compreensão das suas representações visuais e sociais.

Alguns entendimentos e estudos sobre a imagem expressam, de certa forma, uma visão estática do processo de significação da mesma, entendendo-a apenas como registro. Neste trabalho, procuramos tratar as imagens não como uma simples imitação dos objetos, mas como a representação subjetiva dos objetos que integram a realidade.

Merleau-Ponty (1975) já afirmara o caráter polissêmico da imagem, sua permeabilidade receptiva a múltiplas leituras, algo inadmissível por um logocentrismo exacerbado. Nos posicionamos neste ensaio, centrando-nos na possibilidade de estabelecermos uma relação logopática com as imagens, isto é, aproximá-las ao mesmo tempo

\footnotetext{
${ }^{4}$ Vyon (1992), ao discutir a questão dos sujeitos e da intersubjetividade, se refere à mesma como "[...] universos de conhecimentos ou imagens a que os protagonistas reagem, sejam imagens deles mesmos, de seus parceiros ou da situação. A comunicação se desenrola dessa forma sobre um fundo imaginário que as ciências sociais se esforçam em entender através do conceito de representação." (VYON, 1992, p.47). Assim, o sujeito não reage à situação objetiva em si, mas à representação que faz dela e que decorre de conhecimentos precedentes, ou seja, pressupostos culturais. A representação está relacionada à imagem que o sujeito faz de si, dos outros, da situaçã̃o e, por último, das regras e normas de comportamento do grupo social ao qual pertence.
} 
e-Mosaicos - Revista Multidisciplinar de Ensino, Pesquisa, Extensão e Cultura do Instituto de Aplicação Fernando Rodrigues da Silveira (CAp-UERJ)

ANO 1 - V. 1 - N. 1 - JUNHO 2012 - ISSN: 2316-9303

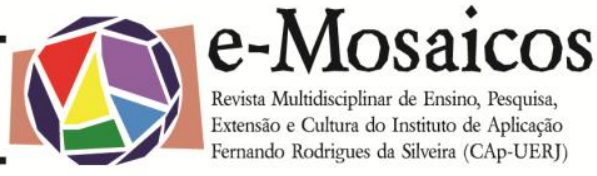

da razão e da emoção.

Deste modo, associamos a imagem com seu potencial de representação ativo e produtivo em mais de um sentido, no qual a representação, além de produzir objetos de que trata, produz sujeitos. Este entendimento se aproxima ao de Lima e Silva (2002), caracterizando a representação como inserida nos aspectos de construção e produção das práticas de significação da realidade, incluindo a mobilização dos recursos imagéticos disponíveis.

Brandão (2003) advoga que o potencial narrativo das imagens visuais e sua exploração negativa pela mídia contemporânea são elementos que justificam a prioridade de formação indivíduos capazes de decodificarem os códigos da nova pragmática da imagem virtual. A manipulação de grande parte da opinião pública torna necessário mobilizar todos os meios formativos que possam contribuir no crescimento do desejo criativo, no desenvolvimento do senso crítico e no discernimento cultural ${ }^{5}$ dos sujeitos.

Por termos esta compreensão, tratamos os envolvidos nos processos sociais como sujeitos complexos, reunindo objetividade e subjetividade. Para tanto, buscamos incorporar, na análise, a liberdade, a ética e a

\footnotetext{
${ }^{5}$ Voltamos a Certeau, para quem a cultura pode ser comparada a uma arte, apresentando-se como um campo de luta multiforme entre o rígido e o flexível. De um lado, ela é aquilo que permanece e, de outro, aquilo que se inventa. Por um lado, existem lentidões e latências e, de outro, há irrupções e desvios. "[...] ela é uma proliferação de invenções em espaços circunscritos [...]" (CERTEAU, 1995, p.19). A cultura reivindicada por Certeau é uma cultura no plural e não aquela que tenta se impor no singular, buscando instaurar-se de modo unificado e de forma totalitária. Certeau afirma ainda que "[...] Sem dúvida, é atualmente um problema novo encontrar-se diante da hipótese de uma pluralidade de culturas, isto é, de sistemas de referência e de significados heterogêneos entre si $[\ldots] "$ " (CERTEAU, 1995, p.142).
}

criatividade. Neste trabalho, também nos apoiamos em Madeira (2000, p.183), ao caracterizamos as representações "como sistemas de interpretação que regem nossa relação com o mundo e com os outros e organizam as comunicações e as condutas sociais.".

Baseando-nos na abordagem teórica das representações sociais fundamentada por Serge Moscovici e Denise Jodelet, centramos estudos em conhecer melhor, a partir do princípio que caracteriza a representação como uma forma de saber prático ligando um sujeito a um objeto, o que/como pensam os envolvidos nos processos educativos a respeito de temas emergentes e latentes no cotidiano escolar, temas estes que podem ou não ser trabalhados de forma mais sistematizada através das disciplinas escolares, mas que não se restringem necessariamente a um ou outro campo de saber específico. Estes questionamentos se aproximam muito dos formulados por Jodelet $(2001$, p.28) a respeito das pesquisas com as representações,

Quem sabe e de onde sabe?; 0 que e como sabe?; Sobre o que sabe e com que efeitos? Estas perguntas desembocam em três ordens de problemáticas: a) condições de produção e de circulação; b) processos e estados; c) estatuto epistemológico das representações sociais. Estas problemáticas são interdependentes e abrangem os temas dos trabaIhos teóricos e empíricos.

Esta abordagem se aproxima do entendimento do cotidiano dos envolvidos, no qual estão incluídas as práticas e táticas da vida cotidiana. As mesmas permitem ampliar 
e-Mosaicos - Revista Multidisciplinar de Ensino, Pesquisa, Extensão e Cultura do Instituto de Aplicação Fernando Rodrigues da Silveira (CAp-UERJ) ANO 1 - V. 1 - N. 1 - JUNHO 2012 - ISSN: 2316-9303

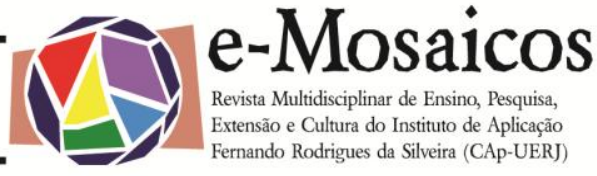

a compreensão das práticas, não apenas como iguais ou diferentes, mas como ações e maneiras de fazer e estar no mundo, que são tecidas à revelia das normas instituídas, instalando dinâmicas e mecanismos sóciopolítico-culturais de ordem-desordemreorganização-desorganização. Este jogo, por sua vez, determina a dinâmica das representações dos membros do grupo por si mesmos, pelos outros que integram este grupo e por outros de grupos diversos (JODELET,1984 e SÁ,1998).

Deste modo, pautamos que a Teoria das Representações Sociais nos permite entender como os conhecimentos advindos do saber científico se transformam no cotidiano, se amoldam em senso comum. Segundo estudos envolvendo as Representações Sociais, as informações são destacadas e deslocadas do campo científico que as originou. Estas informações deixam de ser do grupo de especialistas que as concebeu, sendo apropriadas pelo público que, projetando-as como fatos de seu universo, pode dominá-las. Neste deslocamento há ressignificação em outro contexto, consubstanciando uma apropriação. Na verdade, a tessitura $^{6}$ deste saber científico, acaba sendo não exclusivamente científica. Ela está relacionada com a história e a cultura do sujeito, com as relações das quais o mesmo participa e influi.

Através deste processo, captamos como as representações sociais, uma vez constituídas, se tornam socialmente funcionais, instrumentalizando o saber na interpretação e gestão do ambiente e, refletindo aqueles valores, modelos e os símbolos, tecidos na cultura e incorporados de forma afetiva. Por

\footnotetext{
${ }^{6}$ Argumentada, por Alves (2002, p.13), como "[...] processo de criação de conhecimento no cotidiano [...]", em oposição à Construção, "[...] autodenominado processo moderno de criação do conhecimento na ciência $[\ldots]^{\prime \prime}$.
}

este processo, as representações associamse a categorias e imagens cotidianas e se ligam a pontos de referência conhecidos. De acordo com Arruda (2000, p.72), "as representações sociais constituem uma forma de metabolizar a novidade transformando-a em substância para alimentar nossa leitura de mundo, e assim incorporar o que é novo.". Como todos os processos sociais, inclusive os que incorporam novos conceitos e noções, são marcados pelos valores, modelos e símbolos, os diferentes grupos têm evidenciado, de forma mais ou menos concretizada, mais ou menos explicitada ou sutil, estes valores, crenças, práticas, normas, etc.

Os sentidos atribuídos aos fenômenos e processos sociais são polissêmicos e não possuem uma clareza absoluta e determina$\mathrm{da}$, garantindo uma variedade de pensamentos, ações e condutas baseados em valores diferenciados. Com isto, criam-se redes emaranhadas de significações sobre tais processos e objetos que ora enlaçam as ações, produzindo solidariedades orgânicas, ora resultam em contextos contraditórios que dificultam o entendimento dos mesmos processos, gerando conflitos e frustrações. Ambos, solidariedade e contradição, são sínteses provisórias na criação e atribuição dos sentidos (SILVA, 2003). Tais sentidos são conjugados às informações recebidas ao longo da vida, as quais, por sua vez, vão sendo deslocadas para que os novos conhecimentos apropriados possam ser articulados aos conhecimentos já existentes, naturalizando sua incorporação. Ao mesmo tempo, outros sentidos, permanentemente, dão a ligadura a este emaranhado de informações, conhecimentos, necessidades e demandas fundamentados nos valores que são vivenciados e compartilhados pelos diferentes sujeitos.

A seguir, retrataremos duas experiên- 
e-Mosaicos - Revista Multidisciplinar de Ensino, Pesquisa, Extensão e Cultura do Instituto de Aplicação Fernando Rodrigues da Silveira (CAp-UERJ) ANO 1 - V. 1 - N. 1 - JUNHO 2012 - ISSN: 2316-9303

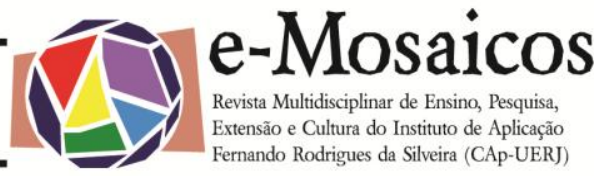

cias que envolveram os sentidos atribuídos por diferentes sujeitos a praticas e temas, que possuem espessura social, relacionados ao meio ambiente e à educação ambiental.

\section{O QUE SE VIVE E 0 QUE SE FAZ COM O QUE SE VIVE: PELAS SUSTENTABILIDADES DE SABERES E FAZERES ARTICULADOS.}

Em abril de 2006, vivemos uma experiência memorável que, de forma abreviada, passamos a descrever. Em oficina ministrada pela professora Claudia Mariza Mattos Brandão (FURG), um grupo de sujeitos inscritos no V Congresso Íbero-americano de Educação Ambiental realizou atividades propostas voltadas para a discussão da temática " $A$ fotografia como recurso para a (re)construção da realidade cotidiana".

$\mathrm{Na}$ oficina, a proposta de pensar a realidade vivida e experimentada por meio das imagens e da fotografia foi apresentada aos participantes. Todavia, as imagens apresentadas em revistas de larga publicação e divulgação foram discutidas e associadas às ideias vinculadas ao meio ambiente e à sustentabilidade socioambiental. Tais imagens foram reconstruídas e remontadas em sequência, em contextos disparados por textos. Ou seja, os textos em associação com as imagens foram retrabalhados pelos sujeitos na tessitura de novos contextos. As preocupações, contradições, complementaridades e sínteses decorrentes deram origens a histórias comuns, tecidas por sujeitos diferentes, que nem se conheciam previamente e que foram mobilizados em função da resolução ou da expressão de preocupações e problemas socioambientais. Vários grupos apresentaram suas sínteses e os grupos interagiram e restabeleceram sínteses ainda mais amplas e complexas. Este trabalho não se esgotou, e somente se interrompeu por razão da exiguidade do tempo.
Ao final do trabalho, havíamos discutido diferentes cenários baseados em enredos e táticas que espelhavam experiências concretas e ações diretas dos participantes sobre a questão socioambiental.

No mesmo ano, associamos tal experiência vivida a ações que desenvolvemos como formadores de professores, em oficina que ministramos para docentes de diferentes disciplinas que atuam na rede municipal da Cidade do Rio de Janeiro. Em tal atividade, congregamos imagens-textos-imagens, ou seja, partimos de imagens produzidas em slides e vídeos, em trabalhos intitulados "Currículo da Escola e Currículo da Vida" e "O berço da desigualdade" desenvolvidos por Michèle Sato, Sebastião Salgado, Cristovam Buarque e Milton Nascimento e Wagner Tiso e apresentados na II Conferência Infanto-Juvenil de Meio Ambiente.

Os trabalhos serviram de base para que os professores presentes às oficinas, em grupos, refletissem sobre seus contextos socioambientais e sobre o contexto nacional e global, no intuito de produzirem seus próprios enredos socioambientais. Para tanto, também aproveitamos textos de autores nacionais que, de forma poética, refletem experiências de vida e cujo conhecimento, muitas vezes é superficialmente aproveitado. Resgatamos trechos de obras literárias de Mario Quintana e Paulo Leminski. Os textos e as imagens, estas últimas provenientes de revistas de grande circulação, em associação, serviram de base ao desenvolvimento dos contextos coletivos e permitiram que os autores e autoras, professores e professoras divulgassem e debatessem sobre suas realidades, em diferentes escalas de tempo e espaço. 
e-Mosaicos - Revista Multidisciplinar de Ensino, Pesquisa, Extensão e Cultura do Instituto de Aplicação Fernando Rodrigues da Silveira (CAp-UERJ) ANO 1 - V. 1 - N. 1 - JUNHO 2012 - ISSN: 2316-9303
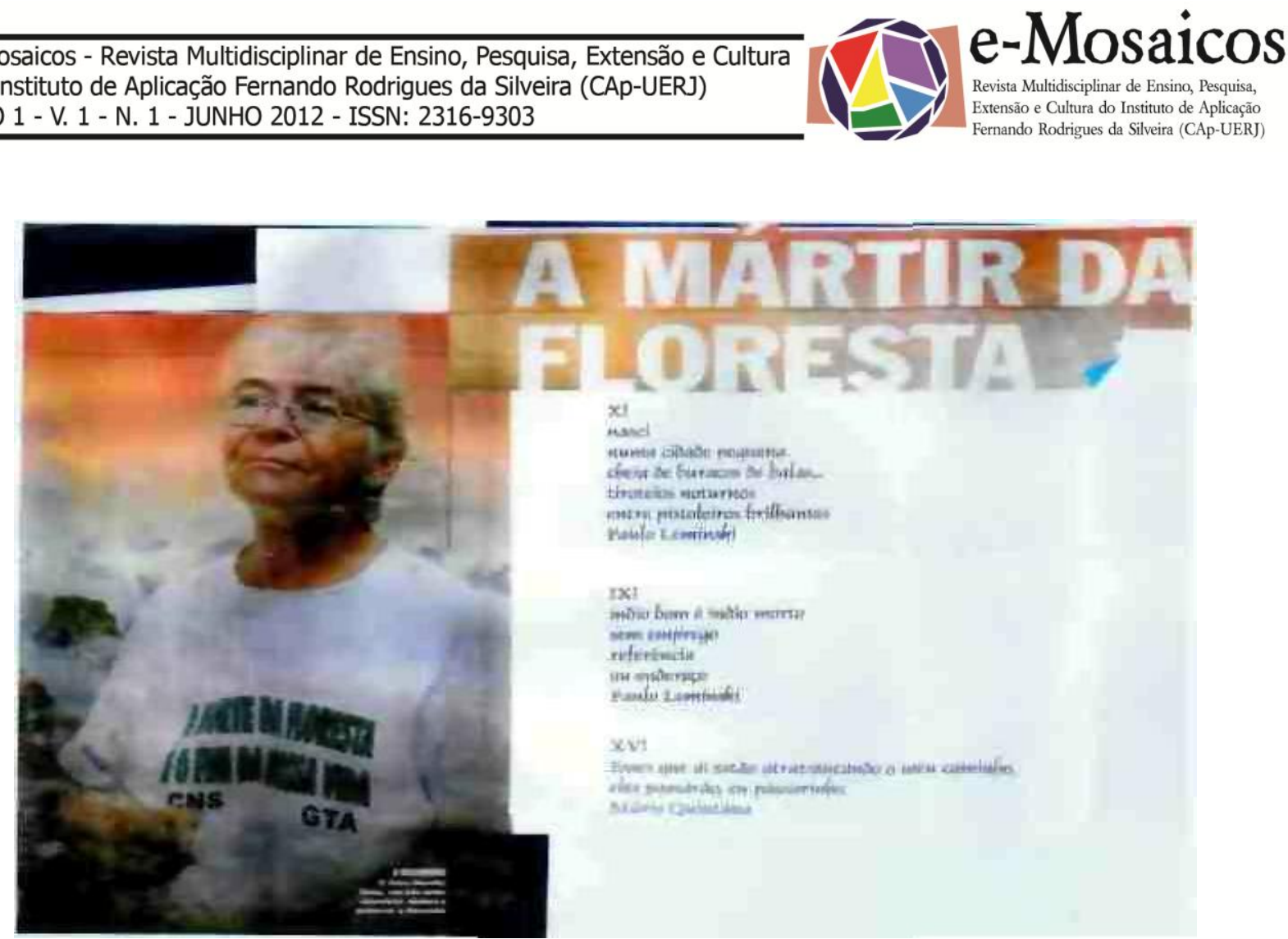

\section{Trabalho produzido por professores da Rede Municipal de Educação do Rio de Janeiro}

A experiência foi extremamente gratificante e associou, em todo seu tempo, o lúdico, o leve e o exato aos objetivos propostos, voltados para a reflexão e para a criação de caminhos possíveis para o tratamento das questões socioambientais, nos temposespaços de sala de aula e, para além deles.

Alguns dos trabalhos produzidos pelos docentes são aqui retratados e, ao final dos mesmos, houve o despertamento em adaptá-los às diferentes realidades vividas, para sua realização junto aos estudantes das redes, com a intermediação dos docentes presentes. Neste sentido, a pequena rede, estabelecida pela parceria de sujeitos que nem sempre já se conheciam, abriu motivação para que outras redes solidárias de produção de conhecimento pudessem ser pensadas. Tudo isso, sem perdermos de vista o rigor necessário à discussão dos conceitos e noções norteadoras dos conhecimentos sobre as condições socioambientais. Ao longo deste texto, apresentamos alguns dos trabalhos produzidos pelos professores, associando imagens obtidas, escolhidas e retrabalhadas aos textos extraídos dos autores citados.

Todas as ações foram permeadas pelo universo da linguagem visual, mormente pelo uso e elaboração de imagens sobre os cotidianos vividos pelos sujeitos. Neste caso, nos basearemos em Barthes (1984), que, voltado principalmente para o entendimento da predisposição humana para a leitura interpretativa das fotos, distinguiu diversos aspectos que lhes são próprios. 

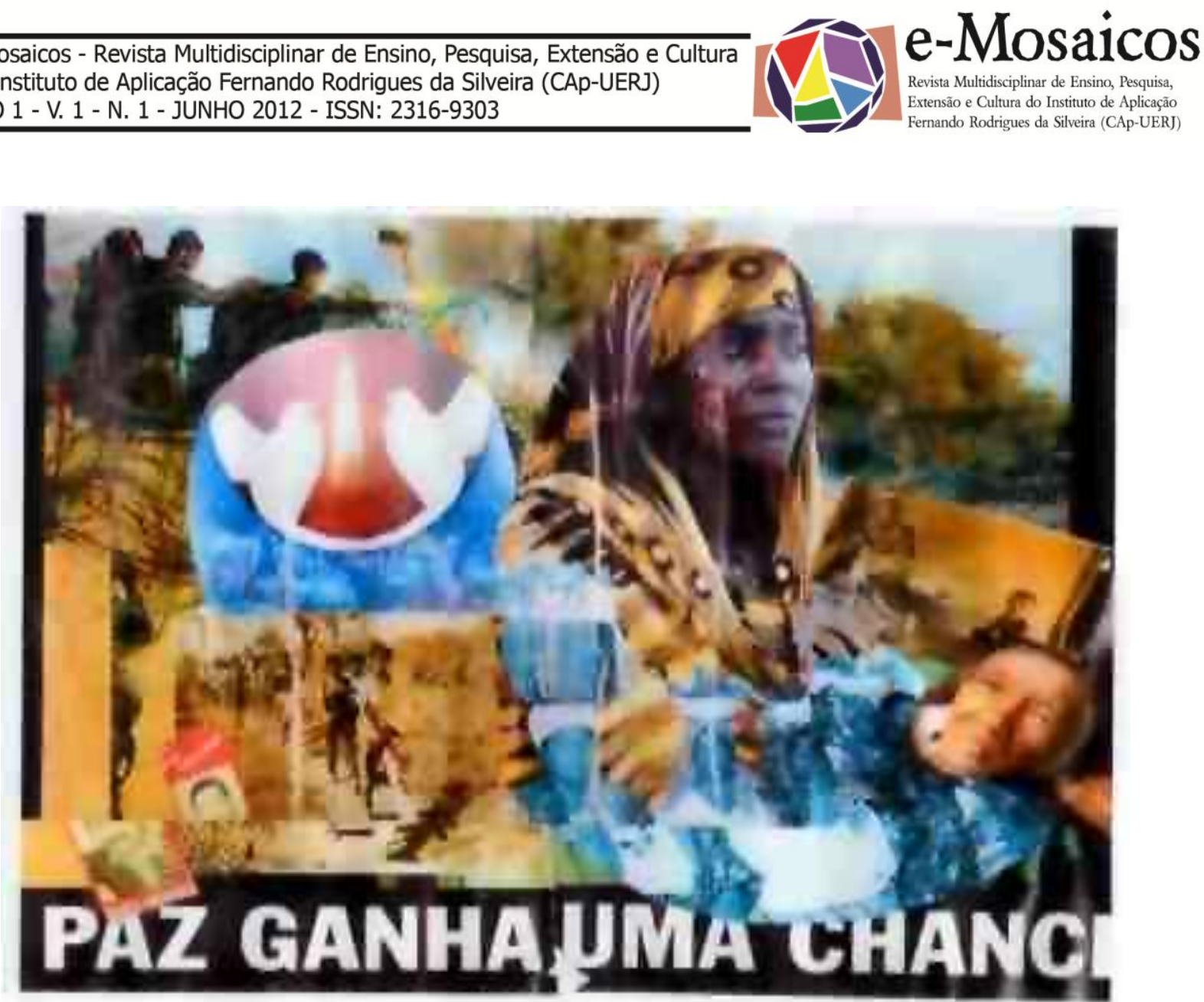

\section{Trabalho produzido por professores da Rede Municipal do Rio de Janeiro}

Captamos o impacto da raridade das imagens nos observadores, e como os mesmos foram capazes de captar uma determinada imagem e que achados ou descobertas os sujeitos realizam, ou não, vas- culhando as imagens. Segundo Costa (2005), podemos nos fundamentar no entendimento de que o apelo afetivo da imagem é tão grande e a cultura imagética de nossa sociedade é tão densa, que ela, por si só, promove um movimento de leitura e de interpretação dos seus conteúdos. 
e-Mosaicos - Revista Multidisciplinar de Ensino, Pesquisa, Extensão e Cultura do Instituto de Aplicação Fernando Rodrigues da Silveira (CAp-UERJ) ANO 1 - V. 1 - N. 1 - JUNHO 2012 - ISSN: 2316-9303
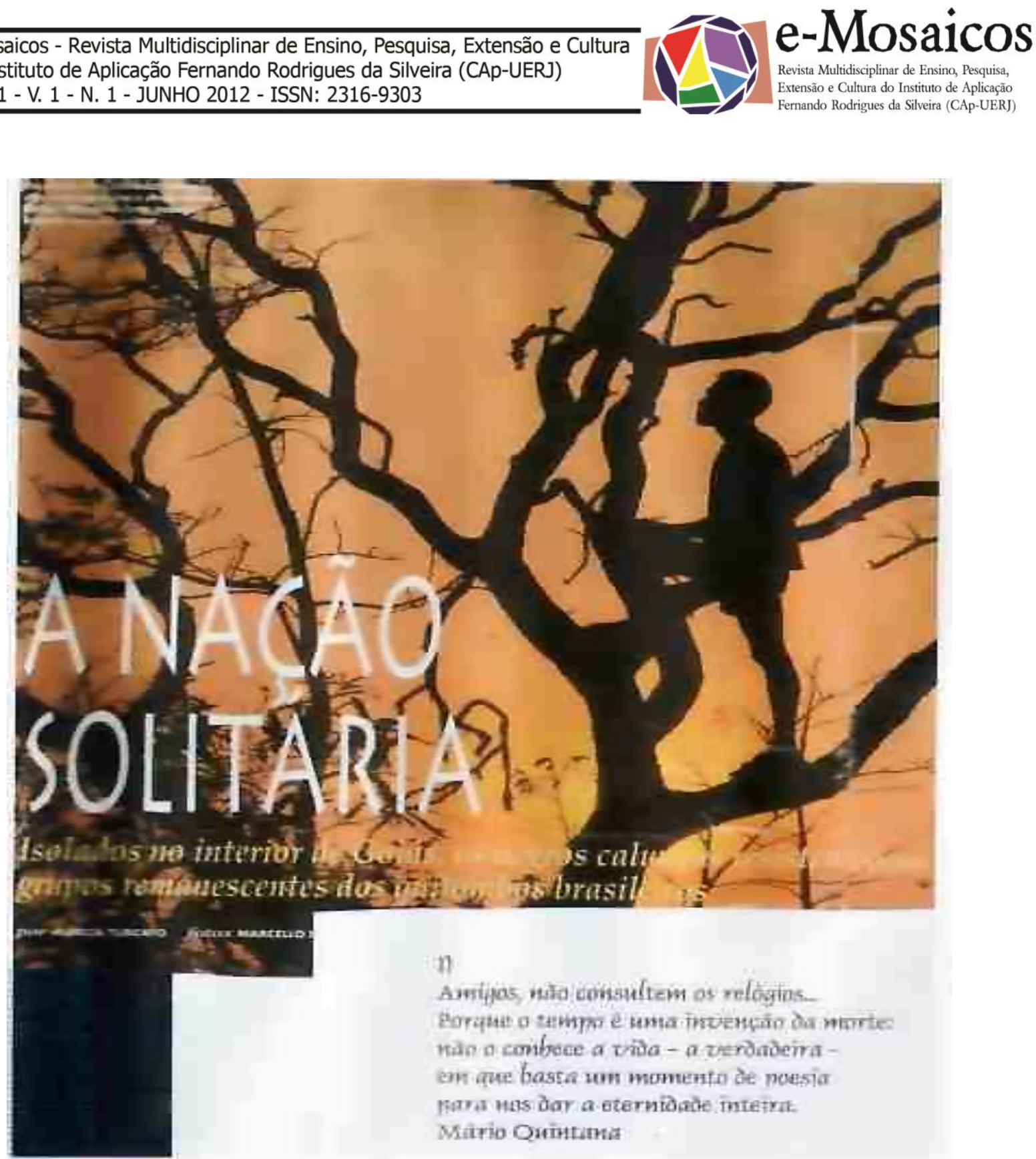

\section{Trabalho produzido por professores da Rede Municipal do Rio de Janeiro}

$O$ encontro entre os sentidos e os saberes sociais transforma a visão em olhar, as vivências em experiências. $O$ desenvolvimento do olhar crítico, das capacidades sensíveis associadas aos entendimentos dos sujeitos, permite a compreensão do mundo através de suas manifestações cotidianas, significando contextos e favorecendo a formação do sujeito estético-crítico. 
e-Mosaicos - Revista Multidisciplinar de Ensino, Pesquisa, Extensão e Cultura do Instituto de Aplicação Fernando Rodrigues da Silveira (CAp-UERJ) ANO 1 - V. 1 - N. 1 - JUNHO 2012 - ISSN: 2316-9303

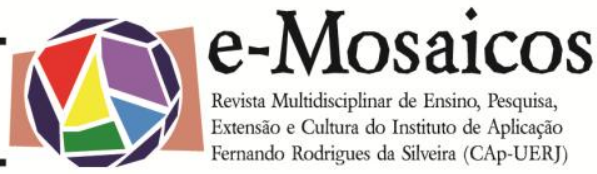

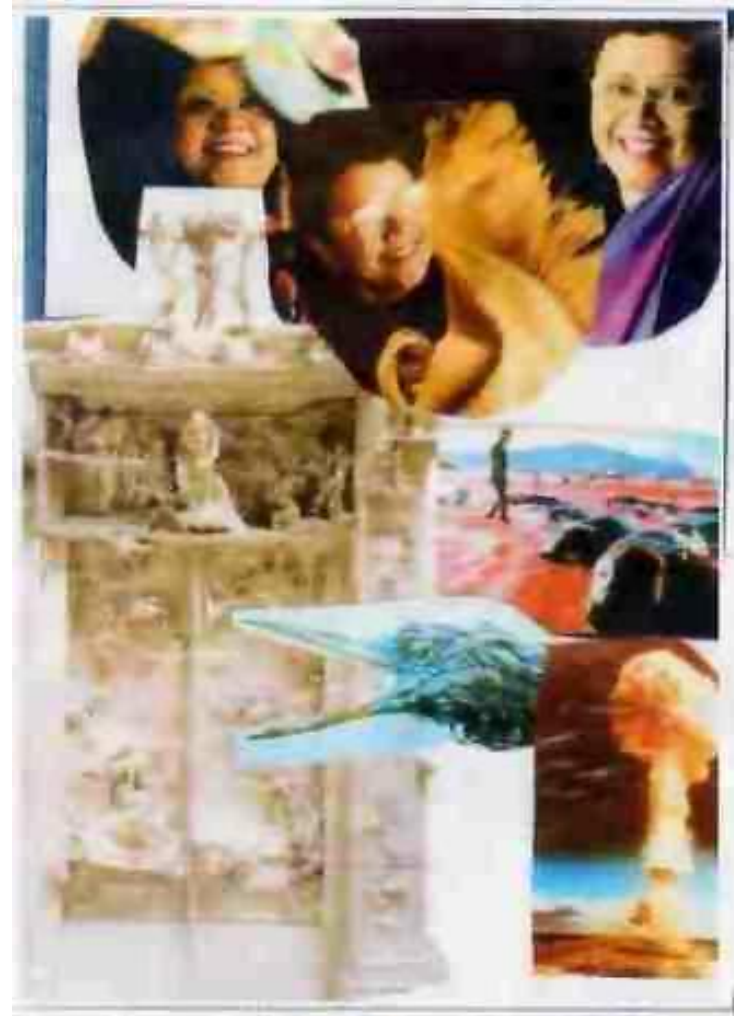

\section{Trabalho produzido por professores da Rede Municipal do Rio de Janeiro}

Assim como Certeau (1994), nos preocupamos em recuperar a forma como os sujeitos ou grupos se apropriam das mensagens disponíveis, assim como os usos que delas fazem (suas táticas). Esses "usos" e "consumos" das representações disponíveis correspondem "modos de proceder da criatividade cotidiana". Neste sentido, embasados neste autor, acreditamos que além da presença e da circulação de uma representação, para o entendimento do que ela é para seus usuários faz-se ainda necessário analisar a sua manipulação pelos praticantes que a fabricam ou não. Deste modo, estaremos apreciando a diferença ou a semeIhança entre a produção da imagem e a produção secundária que se esconde nos processos de sua utilização.

Por esta razão, ao longo das atividades

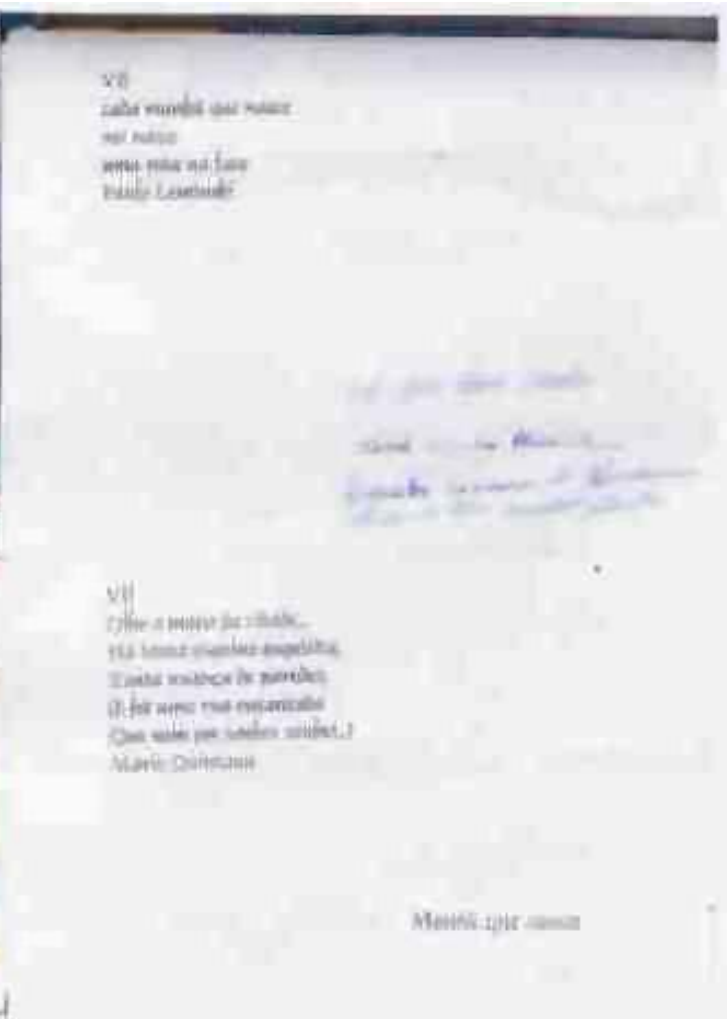

propostas, compartilhamos com os grupos de sujeitos as informações técnicas, visuais, textuais e contextuais ${ }^{7}$ que, segundo Vilches (1997) e Costa (2005), ampliam os entendimento e a competência para a leitura de imagens. São essas competências e entendimentos que fazem das imagens unidades coerentes e com sentido. Deste modo, nossa abordagem pressupõe que utilizaremos não só o olhar, mas toda a sensibilidade dos sujeitos em produzir informações, comparar,

\footnotetext{
${ }^{7}$ Segundo Costa (2005), as informações advindas das imagens podem ser organizadas em níveis. As informações técnicas permitem, por exemplo, distinguir uma foto colorida de outra em branco e preto. As informações visuais dizem respeito à configuração da imagem, ou seja, como ela foi concebida e os critérios estéticos utilizados. As informações textuais são aquelas que obtemos do assunto tratado e da forma como é tratado e, por fim, as informações contextuais correspondem às informações que dizem respeito a tudo aquilo que se sabe sobre as razões e intenções do produtor da imagem ao criá-la.
} 
e-Mosaicos - Revista Multidisciplinar de Ensino, Pesquisa, Extensão e Cultura do Instituto de Aplicação Fernando Rodrigues da Silveira (CAp-UERJ) ANO 1 - V. 1 - N. 1 - JUNHO 2012 - ISSN: 2316-9303

fazer analogias, transformar, desconstruir, projetar e desenvolver memórias visuais. Aqui trabalhamos com o potencial dos sujeitos como produtores das suas próprias imagens, inclusive desconstruindo as imagens existentes sobre seus espaçostempos, tecendo, para os mesmos, novas possibilidades de configuração socioambiental.

Tal como Da Ros et al.(2006), entendemos que a ordem imagética não é mera ilustração ou esteticização do real, mas uma forma de organização das atividades do sujeito, cuja existência auxilia a resolução de planejamento de ações. As ações, por sua vez, tanto podem produzir uma condição de anonimato, quanto de apropriação do conhecimento de forma crítica.

A partir de um conjunto de imagens e representações extraídas em diferentes situações cotidianas, foram propostas reflexões cujas temáticas voltam-se para a possibilidade de construção de um novo pensamento no que se refere ao papel dos grupos, nos seus contextos socioambientais e na sociedade contemporânea. Estes papéis avançam sobre a discriminação e a subordinação social e dinamizam formas alternativas de existência, visando propagar uma cultura emancipatória, a partir de projetos e programas comunitários calcados na alternativa de promoção de sustentabilidades.

Esta possibilidade dá, ao processo de ensinar e aprender, uma característica promissora. Ao invés de nos ameaçar, a imagem pode, como apontaram Da Ros et al. (2006), ser pensada como lugar de produção de frutos, tanto para alunos quanto para professores. Neste sentido, os autores afirmaram que a

produção de imagens por colagens de imagens já existentes, por desenho, pintura, pelo recurso fotográfico - hoje tão di- fundido, abrindo possibilidades inúmeras baseadas nos processos de digitalização - e sua consequente leitura e interpretação, podem ser mediadoras e restituidoras de diálogos horizontalizados, de relações dialógicas entre estes pares e entre os próprios alunos (DA ROS et al., 2006, p. 108).

\section{PARA NÃO PERDERMOS O FOCO...}

O trabalho ora apresentado, em nosso entendimento, reflete uma busca de seu autor por caminhos que não desconsiderem a constituição do conhecimento em rede, sem hierarquizar as formas pelas quais os diferentes sujeitos, nas suas diversas concepções de exprimir e registrar suas culturas, podem, e vêm a atuar no campo educacional e para além dele.

Sujeitos em relação são sempre o foco de toda a prática educativa. Novas práticas, ou a valorização de práticas sensíveis às mudanças e concepções do real, problematizam, desestabilizam, desafiam, mas também reorientam as ações educativas. Talvez seja o caminho que Saramago, citado por Zanella (2006), procurou afirmar no filmedocumentário Janela da Alma (2002), no qual exprimiu que "para conhecer algo é necessário dar-lhes a volta.". Zanella afirma ser impossível buscar a verdade por meio de uma volta inteira, pois a realidade é polissêmica, mas nos é possível que o exercício de olhar e sentir por outros ângulos e por outros aspectos se dê, mesmo sem sairmos do lugar. 
e-Mosaicos - Revista Multidisciplinar de Ensino, Pesquisa, Extensão e Cultura do Instituto de Aplicação Fernando Rodrigues da Silveira (CAp-UERJ) ANO 1 - V. 1 - N. 1 - JUNHO 2012 - ISSN: 2316-9303

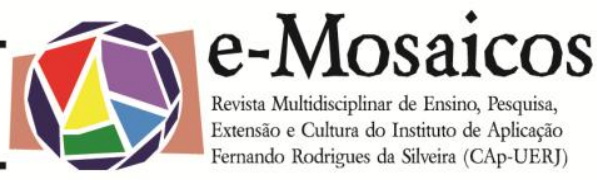

\section{REFERENCIAIS BIBLIOGRÁFICOS}

ABBAGNANO, N. Dicionário de Filosofia. Tradução Alfredo Bosi. 2 ed. São Paulo: Martins Fontes, 1998.

ALVES, N. A experiência da diversidade no cotidiano e suas consequências na formação de professoras. In: VICTORIO FILHO, A. \& MONTEIRO, S.C.F. (Org.). Cultura e conhecimento de professores. Rio de Janeiro: DP\&A. 2002. p.13-29.

ARRUDA, A. Representações sociais e movimentos sociais: grupos ecologistas e ecofeministas do Rio de Janeiro. In: Moreira, A. S. P. \& Oliveira, D. C. (Org.). Estudos Interdisciplinares de Representação Social. Goiânia: AB-Editora, 2000. p. 71-86.

BAKHTIN, M. Estética da Criação Verbal. São Paulo: Martins Fontes Editora Ltda, 1997.

BARTHES, R. A câmara clara. Rio de Janeiro: Nova Fronteira,1984.

BAUDRILLARD, J. O crime perfeito. Lisboa: Relógio d'Águalilée, 1995

BRANDÃO, C.M.M. Arte-Educação Ambiental: na busca de uma cidadania ecológica.

In: Educação Ambiental em Ação, Rio Grande, RS, no 5, ano 2, 2003.

CALVINO, I. Seis Propostas para o Próximo Milênio. São Paulo: Companhia das Letras, 1990. 141p.

CANCLINI, N. G. Culturas Híbridas. São Paulo: Edusp, 1998.

CERTEAU, M. de. A invenção do cotidiano. Petrópolis: Vozes, 1994. 352p.

. A Cultura no Plural. Campinas:

Papirus, 1995. 253p.

COSTA, C. Educação, imagem e mídias. São Paulo: Cortez, 2005. 198p.

DA ROS, S. Z.; LENZI, L.H.C.; SOUZA,
A.M.A. \& GONÇALVES, M.M. O ensinar e aprender, a pesquisa e a "sociedade da imagem": apontamentos. In: .(Orgs.) Imagem: intervenção e pesquisa. Florianópolis, Editora da UFSC:NUP/CED/UFSC, 2006.

DEBORD, G. A Sociedade do Espetáculo. Rio de Janeiro: Contraponto, 1997.

DEBRAY, R. Vie et mort de L 'image: une histoire $d u$ regard en Occident.Paris: Gallimard, 1992.

FISCHMAN, G. E. Reflexões sobre imagens, cultura visual e pesquisa educacional. In: Ciavatta, M. \& Alves, N. (Orgs.). A leitura de imagens na pesquisa social. São Paulo: Cortez , 2004. p. 109-125.

FULCHIGNONI, E. La Civilisation de l'image. Paris: Payot, 1972.

GÓMEZ, G. O. Del Acto al proceso de Ver Televisión: una aproximación epistemológica. Cuadernos de Comunicación y Práticas Sociales. Nro. 2, 1991.

HARVEY, D. Condição Pós-Moderna: uma pesquisa sobre as origens da mudança cultural. 9a ed. São Paulo: Edições Loyola, 2000.

JAMESON, F. Pós-modernismo: a lógica cultural do Capitalismo Tardio. São Paulo: Ática, 1997.

JODELET, D. Representações Sociais: um domínio em expansão. In:

(Org.). As representações Sociais. Rio de Janeiro: EdUERJ, 2001. p. 17-44.

Représentations Sociales: phénomènes, concept et théorie. In: MOSCOVICI, S (Org.). Psychologie sociale. Paris: PUF, 1984. p. 357-378.

LARROSA, J. Pedagogia profana: danças, piruetas e mascaradas. Porto Alegre: Contra*Bando, 1998. 253p. 
e-Mosaicos - Revista Multidisciplinar de Ensino, Pesquisa, Extensão e Cultura do Instituto de Aplicação Fernando Rodrigues da Silveira (CAp-UERJ) ANO 1 - V. 1 - N. 1 - JUNHO 2012 - ISSN: 2316-9303

LIMA, C. A. de \& SILVA, N. M. B. da. Imagens equivalentes. In: XXV Congresso Brasileiro de Ciências da Comunicação, 2002, Salvador. Anais... Salvador: INTERCOM, 2002. p. 1-15.

MACHADO, A. O Quarto Iconoclasmo e outros ensaios hereges. Rio de Janeiro: Rios Ambiciosos, 2001. 160p.

MADEIRA, M.C. Meninos de rua e a construção de sentido de educação. In: GRANATO, T. A. C. (Org.). A educação em questão: novos caminhos para antigos problemas. Petrópolis: Vozes-UCP, 2000. p. 182-194.

. Representações Sociais e Educação: importância teórico-metodológica de uma relação. In: MOREIRA, A. S. P. (Org.). Representações Sociais: teoria e prática. João Pessoa: Ed. Universitária UFPB, 2001. p. 123-144.

. \& ALLOUFA, J. Representações sociais e Educação: que relação é esta ? In: II COLÓQUIO FRANCO-BRASILEIRO EDUCAÇÃO E LINGUAGEM, 1995, Natal. Anais... Natal: Université de Caen/ EDUFRN (RN), 1995. p. 11-15.

MARTIN-BARBERO, J. De los Medios a las Mediaciones. Barcelona: G. Gili, 1993.

MERLEAU-PONTY, M. $O$ olho e o espirito. São Paulo: Abril Cultural, 1975.

SÁ, C. P. de. A construção do objeto de Pesquisa em Representações Sociais. Rio de Janeiro: EdUERJ, 1998. 110p.

SILVA, L. T. Os sentidos atribuídos pelos professores de Geografia à Educação Ambiental: olhares sobre a questão. 2003. Dissertação (Mestrado em Educação), Faculdade de Educação, Universidade Católica de Petrópolis, 2003, $262 \mathrm{f}$.

UEÓCKA, L. G. A força das imagens na Campanha civilista: representações em fotografias e caricaturas. Colloquium Huma- narum, Presidente Prudente: UNOESTE, v., n.1, p. 63-71, jul./ dez., 2003.

VILCHES, L. La lectura de la imagen. Barcelona: Paidós, 1997.

VYON, R. La Communication Verbale: analyse des interactions. Paris: Hachette, 1992.

ZANELLA, A.V.Sobre olhos, olhares e seus processos de (re)produção. In: Lenzi, L.H.C.; Da Ros, S. Z.; Souza, A.M.A. \& Gonçalves, M.M.(Orgs.) Imagem: intervenção e pesquisa. Florianópolis, Editora da UFSC:NUP/CED/UFSC, 2006.

${ }^{1}$ lincolnt@uerj.br - Bacharel em Geografia pela Universidade Federal do Rio de Janeiro (1990), Licenciatura em Geografia pela UFRJ (1992), Especialização em Políticas Territoriais do Estado no Rio de Janeiro (UERJ), Mestrado em Educação pela Universidade Católica de Petrópolis (2003) e Doutorado em Educação pela USP (2012). Atualmente, é Professor Assistente da Universidade do Estado do Rio de Janeiro / Instituto de Aplicação Fernando Rodrigues da Silveira - CAp-UERJ. Tem experiência na área de Educação, atuando principalmente nos seguintes temas: educação, ensino da geografia, formação de professores, geografia e educação ambiental, gestão e administração escolar e educação a distância. De março de 2004 a fevereiro de 2008 dirigiu o Instituto de Aplicação da UERJ CApUERJ, cargo que ocupa atualmente. Esteve à frente do Centro de Educação e Humanidades da mesma Universidade e possui experiência acumulada na participação nos Conselhos Superiores da Universidade. Também integrou comissões que discutiram o financiamento público e a prestação de serviços na Universidade, a adoção de políticas afirmativas, a reforma universitária e a elaboração do plano de carreiras dos servidores técnico-administrativos e dos docentes. Continua atuando junto à Educação Básica e às formações docentes inicial e continuada. Também é membro do Conselho Estadual de Educação do Rio de Janeiro. 